\title{
Mixing Suspensions in Slender Tanks
}

\author{
F. Rieger, E. Rzyski
}

Industrial suspension mixing processes are carried out both in standard tanks $(H / D=1)$ and in the tanks with height $H / D>1$. When only one impeller is used in such slender tanks, it may be difficult to produce a suspension of desired homogeneity. Hence it may be necessary to install a larger number of impellers on the shaft.

The aim of this study was to explain the mechanism of suspension formation in slender tanks $(H / D=2)$ with an increased number of impellers. On the basis of the solid bed height on the tank bottom, the position of the suspension - water interface and the concentration profile of solid particles in the suspension (standard deviation of solid body concentration) the operation of the impellers was estimated and conclusions were drawn on how and at what distance from each other to install them were presented.

The location of the upper, highest impeller appeared to be specially significant. On the basis of this study it is recommended to locate the upper impeller so that its distance from the free liquid surface is less than $0.8 \mathrm{D}$. It was found that such a position of the highest impeller was also advantageous from the energy point of view.

Keywords: agitation, agitated tank, mixing, suspension.

\section{Introduction}

In the chemical and food industry, the aim of mixing is often to obtain a solid suspension. In some cases, high homogeneity of the produced suspensions is also required [1]. For mixing suspensions, both standard slender tanks of $H / D=1$ and tanks with higher $H / D$ ratios are used. Application of tanks of the latter type enables rational use of a working surface.

It may be difficult to obtain the desired homogeneity of the suspension (particularly for slender tanks with only one impeller or in the case of coarse grained suspensions) so it will be necessary to install more impellers on the shaft.

The aim of this study is to explain the process of producing suspensions in slender tanks $(H=2 D)$ equipped with one or more impellers.

\section{Experimental}

Experiments were carried out in a cylindrical flat-bottomed (glass) tank of diameter $D=0.2 \mathrm{~m}$, filled with a liquid to a height of $H=D$ or $H=2 D$. In the tank there were four standard baffles and a pitched four-blade impeller $\left(\alpha=45^{\circ}\right)$. The diameter of these impellers was $d=D / 3$.

Measurements were made using one to five impellers, with the bottom impeller being always placed at a distance of $0.5 d$ from the tank bottom. The distances between the impellers with several rotors were $\ell=0.5 d, d$ or $1.5 d[2,3]$.

Water suspensions of glass ballotine of diameter $\delta=1.34$ and $0.42 \mathrm{~mm}$ in an amount adequate for volumetric solid concentration equal to $2.5 \%$ were used as model suspensions. The height of the layer of unsuspended particles $\left(\mathrm{h}_{\mathrm{v}}\right)$ close to the wall and the level of the suspension - water interface $\left(h_{s}\right)$ were determined visually. These quantities are shown in Fig. 1.

Local concentrations of solid particles at different levels of suspension were measured by conductometry [4]. To estimate quantitatively the suspension homogeneity on the basis of these measurements, relative standard deviation $\sigma$ was calculated. It was defined by the equation

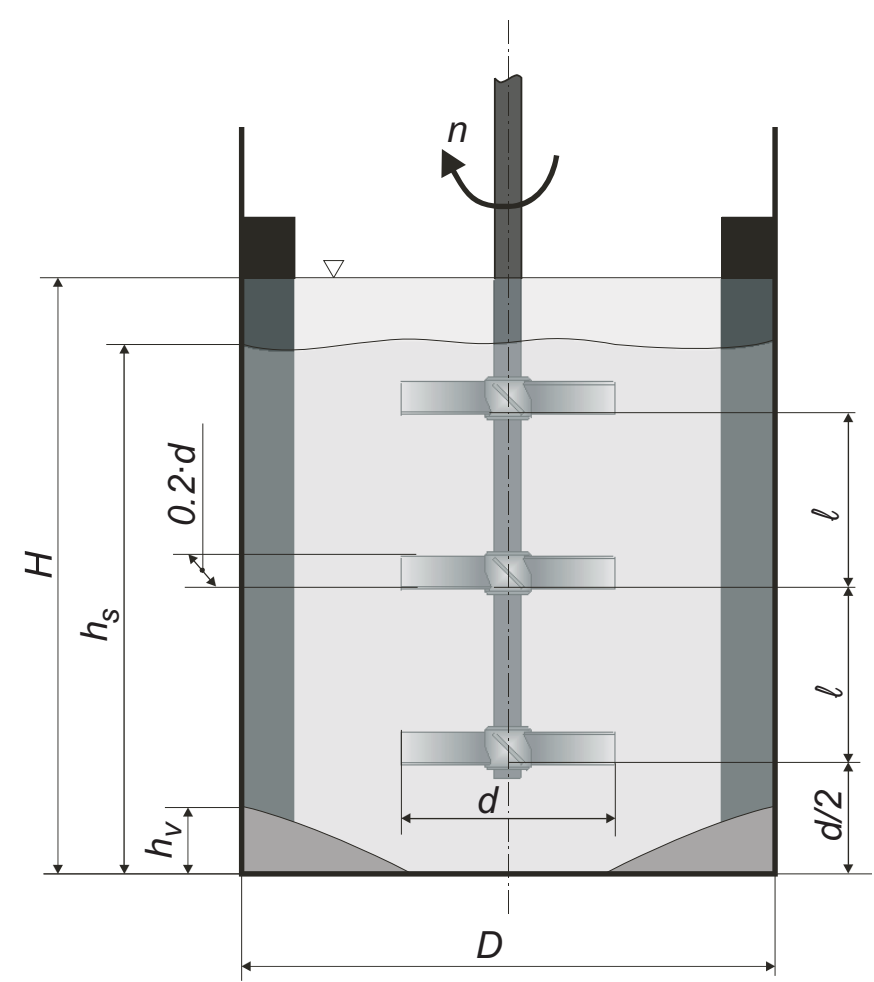

Fig. 1: Schematic diagram of the tank

$$
\sigma=\frac{1}{c_{\mathrm{m}}} \sqrt{\frac{\sum_{i=1}^{N}\left(c_{\mathrm{i}}-c_{\mathrm{m}}\right)^{2}}{N}}
$$

where $N$ - number of measuring points in the suspension.

The ability of an impeller to form a suspension was estimated on the basis of a dimensionless criterion which determined the power required to introduce solid particles into the suspension. This criterion is an extension of the dimensionless number proposed previously [5] and has the following form: 
$\Pi_{\mathrm{s}}=\frac{P}{\rho_{\mathrm{z}}} \sqrt{\left(\frac{\rho}{g \cdot \Delta \rho}\right)^{3} \frac{1}{\left(D^{2} H\right)^{7 / 3}}}=P o \sqrt{\left(\mathrm{Fr}^{\prime}\right)^{3}\left(\frac{d}{D}\right)^{7}\left(\frac{D}{H}\right)^{7 / 3}}$

Values of power number Po for multiple pitched four-blade turbines were calculated from the following relation recommended in [6]

$$
P o=P o_{1}+(j-1) P o_{\mathrm{s}}
$$

where $P_{o_{1}}$ is the power number of the bottom impeller and $\mathrm{Po}_{\mathrm{s}}$ are the power number values of the higher impellers. The value of the bottom impeller power number for pitched four-blade turbine $P_{o_{1}}=1.36$, the $P_{o_{\mathrm{s}}}$ values depend on $\ell / d$ and they are listed in Table 1 .

Tab. 1: Values of power number $P_{o_{\mathrm{s}}}$ for tested four-blade turbines

\begin{tabular}{|l|c|c|c|}
\hline Ratio of $\ell / d$ & 0.5 & 1.0 & 1.5 \\
\hline$P o_{\mathrm{s}}$ & 0.71 & 0.82 & 0.88 \\
\hline
\end{tabular}

\section{Results}

The results obtained are presented graphically. Fig. 2 shows the results of measurements for a standard tank with one impeller. Fig. 2a illustrates measured heights $\left(h_{\mathrm{v}}\right.$ and $\left.\mathrm{h}_{\mathrm{s}}\right)$ as a function of the frequency of the impeller rotation. At rotation frequency $n=200 \mathrm{~min}^{-1}$ solid particles are introduced into the suspension. The rotation frequency at which all solid particles are separated from the bottom (critical frequency of the impeller rotation [3]) is $1000 \mathrm{~min}^{-1}$. Fig. 2b shows the volumetric concentration of the solid particles at different levels of liquid in the tank just for this frequency. Though all solid particles are in the suspension, and the level of separation reaches the height of the liquid in the tank, there are differences in the concentration, and the suspension is not homogeneous. A further increase in the rotation frequency causes an increase in homogeneity, as follows from Fig. 2c, which shows the relative standard deviation for different frequencies of rotation. A quick decrease in the relative standard deviation which takes place between 900 and $1000 \mathrm{~min}^{-1}$ corresponds to the disappearance of the solid particles from the tank bottom.

The application of a larger number of impellers on one shaft leads to a decrease in the critical frequency of rotation corresponding to separation of all particles from the bottom. This is reflected in the graph presented in Fig. 3a. Although

a)

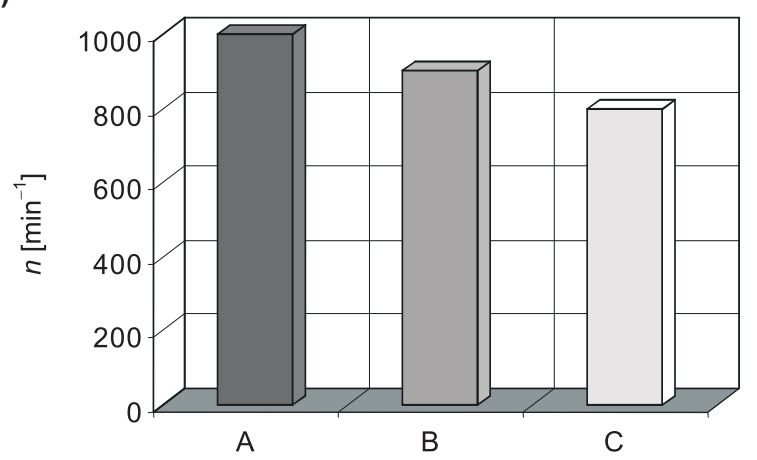

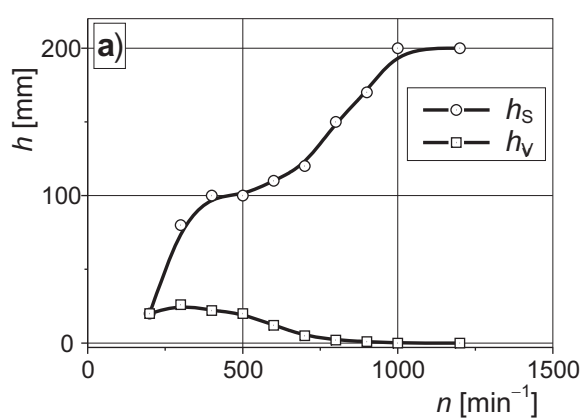
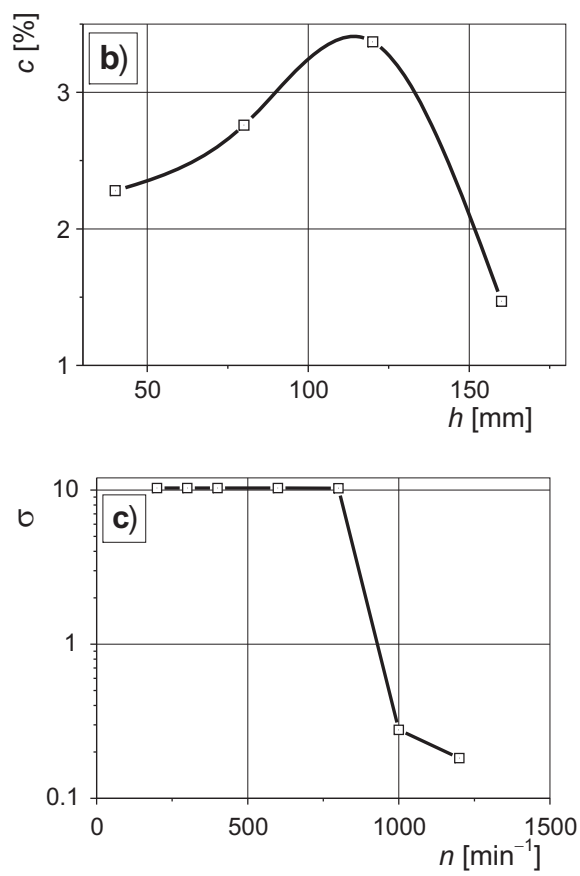

Fig. 2: Mixing a suspension of particles $d=1.34 \mathrm{~mm}$ (standard tank $H=D$ with one impeller): a - dependence of heights $h_{\mathrm{v}}$ and $h_{\mathrm{s}}$ on the frequency rotation; b - solid concentration on different levels of liquid; c - dependence of standard deviation on the impeller rotational frequency

the number of impellers increases, the power needed to put them in motion does not change significantly (Fig. 3b). However, in such a case the homogeneity increases. This follows from a comparison of the concentration distribution in the tank for rotation frequency $n=1000 \mathrm{~min}^{-1}$ for the tested impellers and the impact of the relative standard deviation

b)

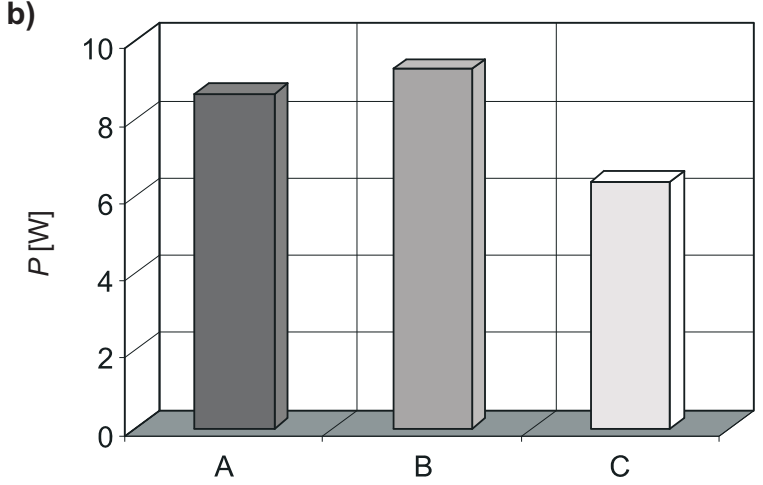

Fig. 3: Effect of increasing the number of impellers (particles $\delta=1.34 \mathrm{~mm}$, tank $H=D$ ): a - values of rotational frequency of impellers; $\mathrm{b}$ - values of mixing power (A - one impeller; $\mathrm{B}$ - two impellers, $\ell=0.5 d$; C - two impellers, $\ell=d$ ) 

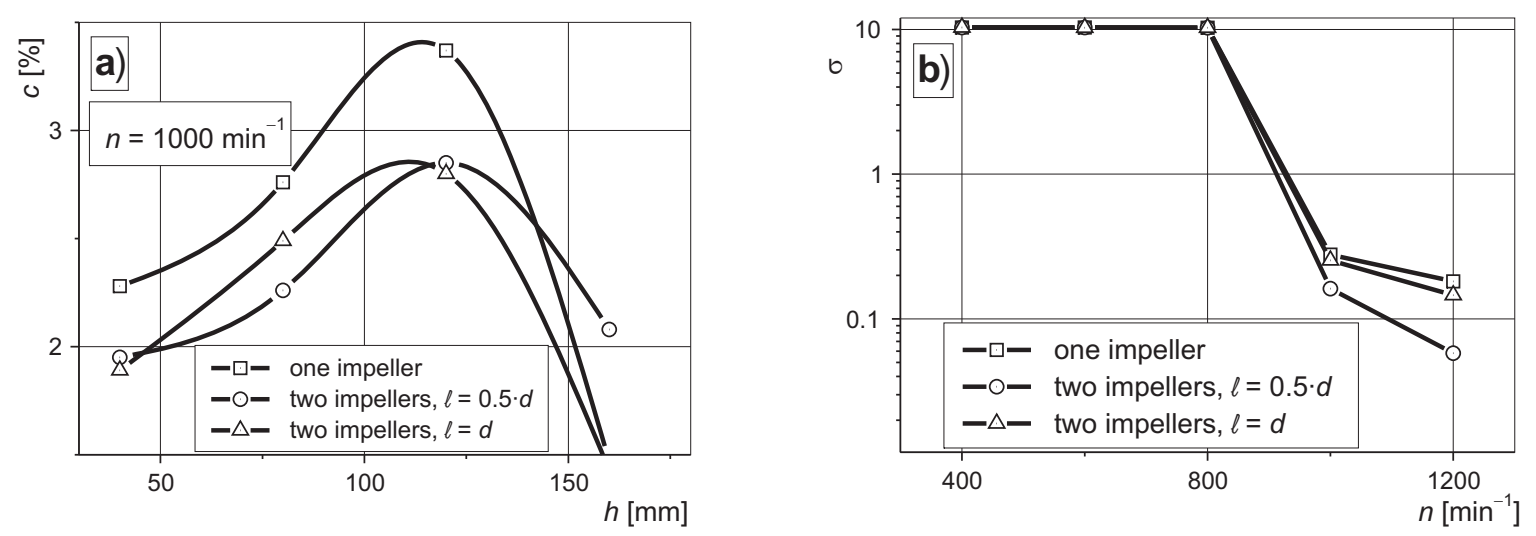

Fig. 4: Mixing the suspension using one or two impellers (particles $1.34 \mathrm{~mm}$, tank $H=D$ ):

$\mathrm{a}$ - concentration distribution at $n=1000 \mathrm{~min}^{-1}, \mathrm{~b}$ - mean standard deviation for different rotation frequency

(Figs. 4a and 4b). It follows from these figures that a smaller distance between the impellers (equal to $0.5 d$ ) is more advantageous for homogeneity than a distance equal to $d$.

In a standard tank with one impeller only, suspensions can be produced which - although non-homogeneous - have solid particles dispersed along the whole liquid height. In more slender tanks $(H / D=2)$ the separation level is much below the liquid height in the tank (solid particles reach only slightly above half the liquid height), and in most of the upper half almost pure liquid is found (cf. Fig. 5).

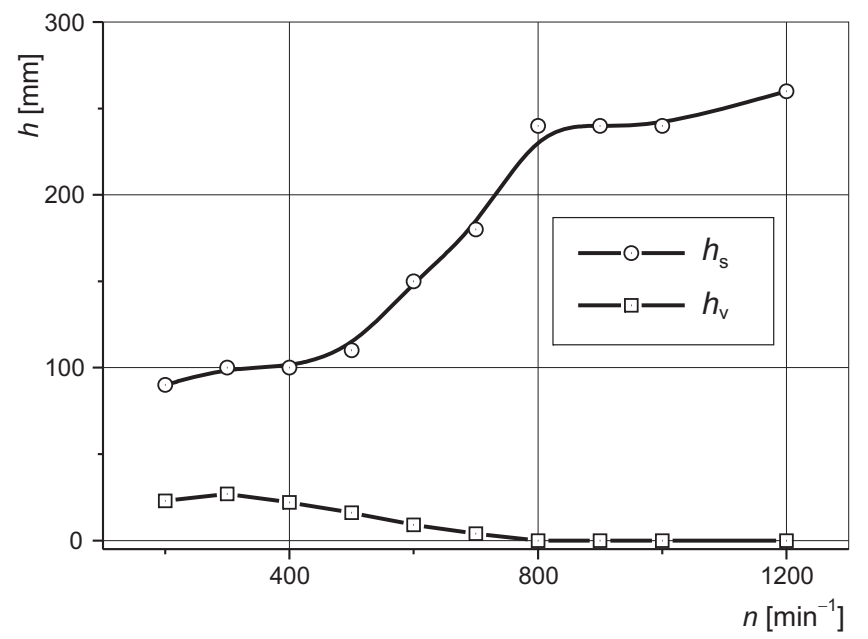

Fig. 5: Interface and height of the layer of solid particles (particles $1.34 \mathrm{~mm}$, tank $H=2 D$, one impeller)

When two impellers are located on the shaft, the critical frequency of the impeller rotation is not much reduced and homogeneity does not increase. Fig. 6 illustrates the dependence of the relative standard deviation on rotation frequency for one and for two impellers placed at different distances from each other. However, we do not recommend such a solution, because the use of two impellers is connected with an increase in energy consumption.

A clear increase in the homogeneity of the suspension is achieved when three impellers are used. Fig. 7 illustrates the relative standard deviation for one, two and three impellers (at a distance of $1.5 d$ from each other). This homogeneity increase is also a result of the distributions of solid body concen-

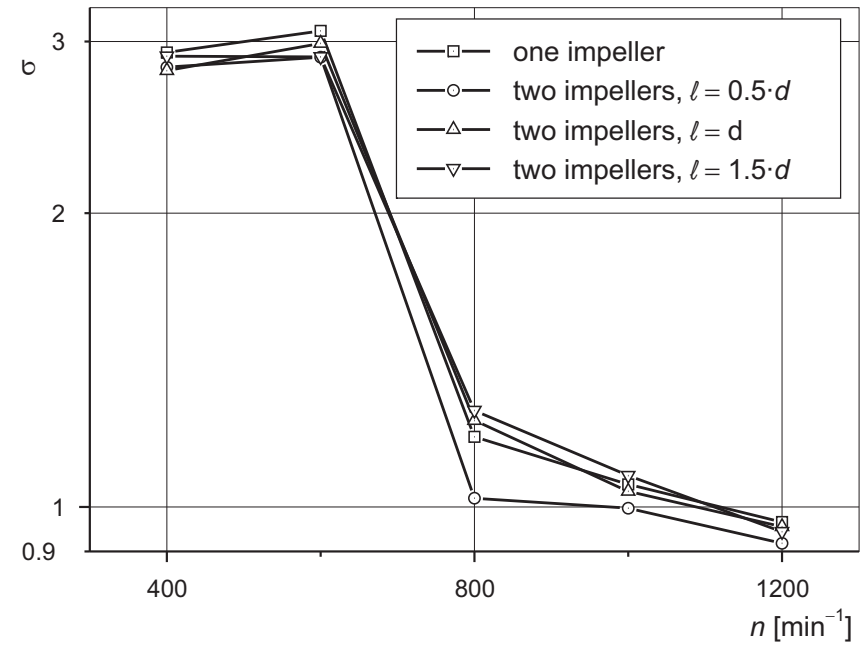

Fig. 6: Relative standard deviation of suspension concentration for one or two impellers $(\delta=1.34 \mathrm{~mm}$, tank $\mathrm{H}=2 D)$

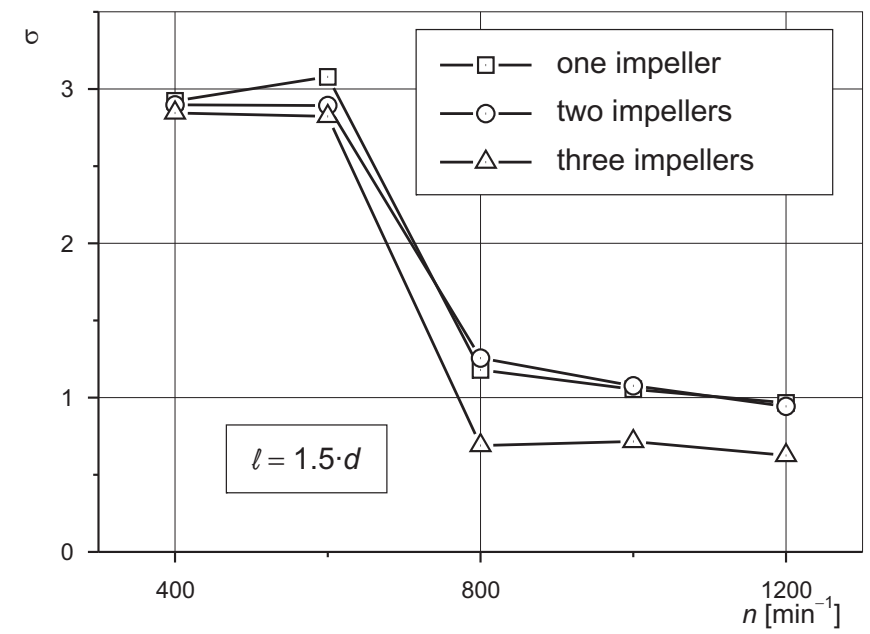

Fig. 7: Relative standard deviation of suspension concentration for different number of impellers in the tank $H=2 D$ $(\delta=1.34 \mathrm{~mm}, \ell=1.5 d)$

tration shown in Figs. 8 and 9. At above of the liquid height in the tank with three impellers, there is a suspension with very low concentration of solid body $(c \approx 0)$. This refers, however, to larger particles only $(\delta=1.34 \mathrm{~mm})$, because when 


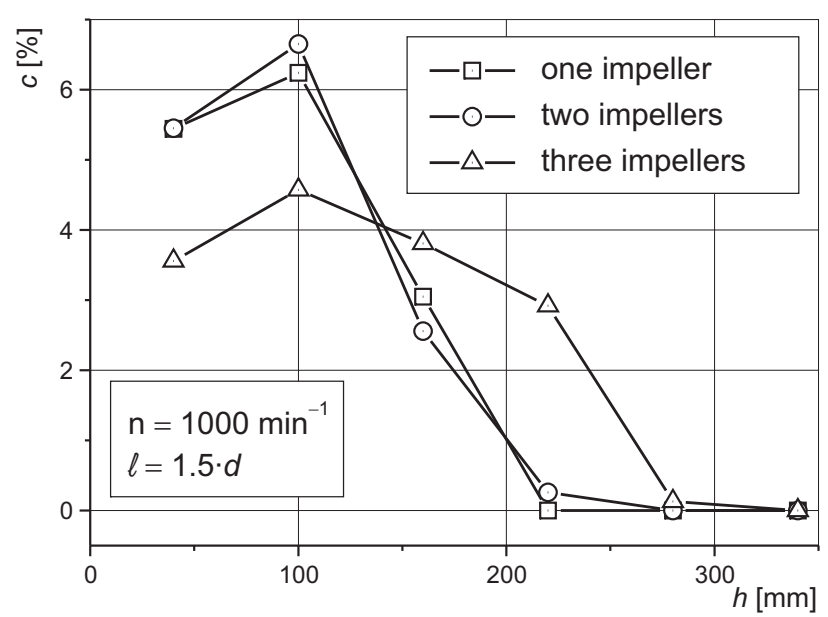

Fig. 8: Distribution of solid concentration for the impellers in Fig. 7

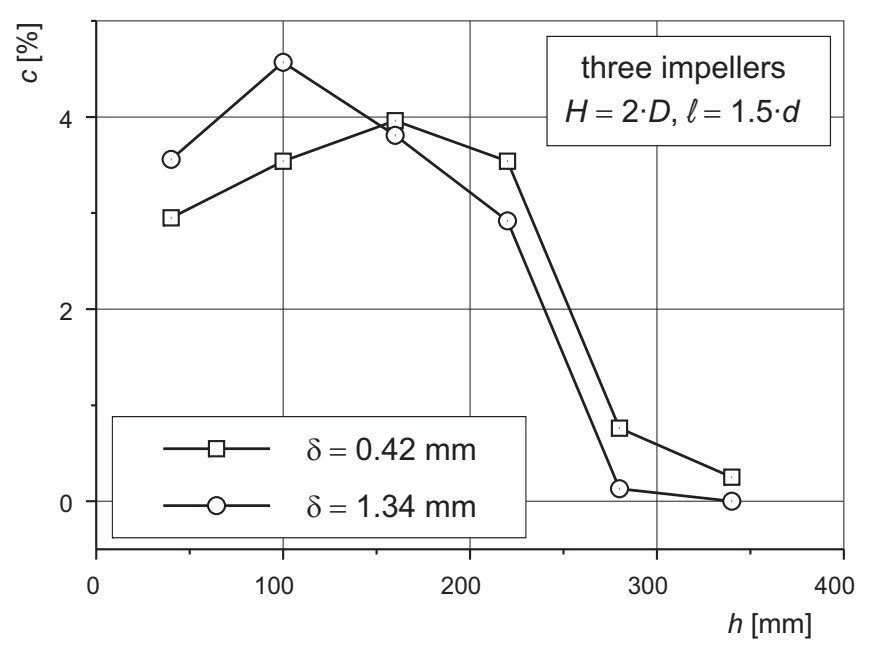

Fig. 9: Comparison of concentration distribution for different solid particle sizes $(\operatorname{tank} H=2 D)$

a suspension of fine particles is formed $(0.42 \mathrm{~mm})$ the suspension - water interface reaches the surface of the liquid in the tank and the concentration distribution reveals growing homogeneity of the suspension.

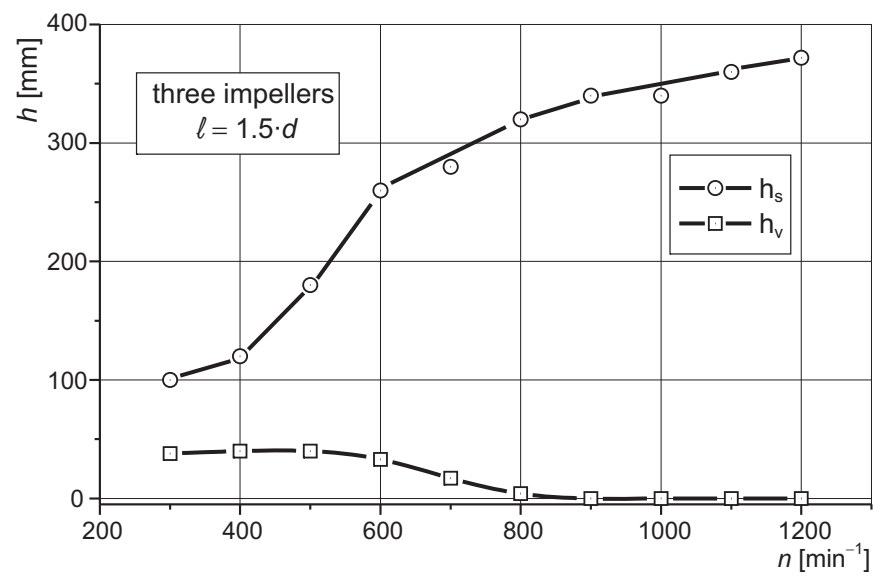

Fig. 10: Interface and height of the layer of solid particles ( $\delta=1.34 \mathrm{~mm}$, tank $H=2 D$, three impellers)
The application of three impellers also gives the interface $\mathrm{h}_{\mathrm{s}}$, which almost reaches the height of tank filling, as shown in Fig. 10. To draw further conclusions, experiments were carried out with a larger number of impellers.

A comparison of the concentration profile of the suspension obtained using several impellers placed at a distance of $\ell=d$ from each other (for rotation frequency $n=1000 \mathrm{~min}^{-1}$ ) is shown in Fig. 11. It follows that partial improvement of homogeneity is already achieved when three impellers are used. A significant increase in homogeneity occurs only when four impellers are applied.

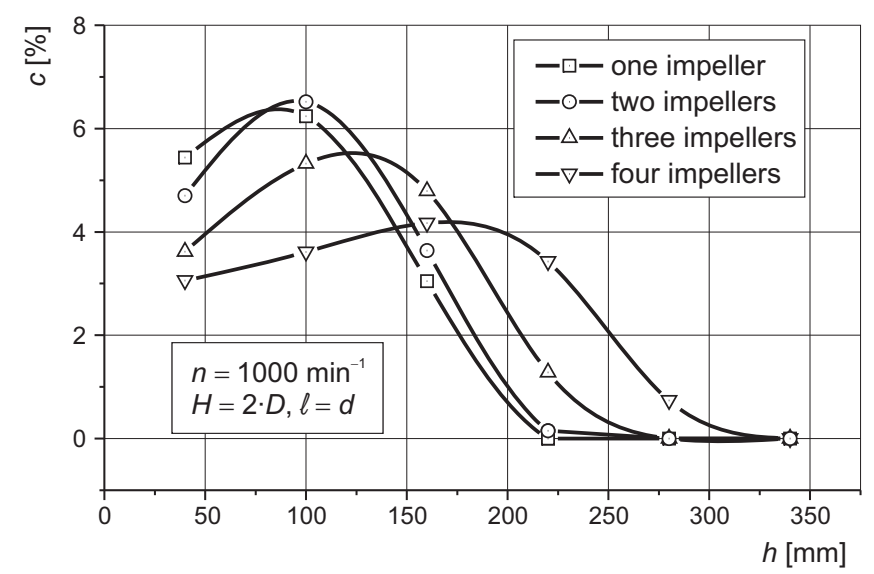

Fig. 11: Distribution of suspension concentration for a different number of impellers $(\delta=1.34 \mathrm{~mm}$, tank $H=2 D, \ell=d)$

Fig. 12 gives a comparison of the distribution of suspension concentration for the same rotation frequency $\left(1000 \mathrm{~min}^{-1}\right)$ for impellers located at a distance of $\ell=0.5 d$ from each other. In this case a distinct improvement in the concentration distribution of the suspension is obtained for a maximum number, i.e., five impellers.

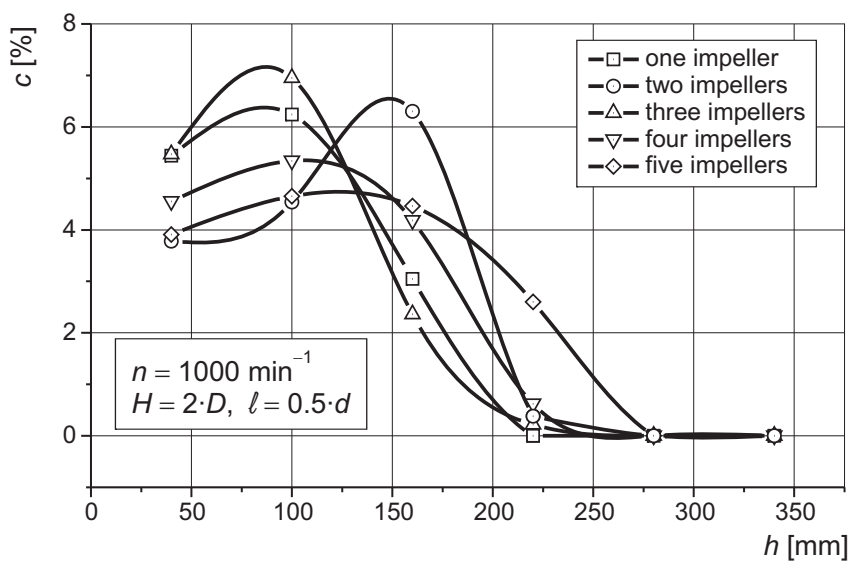

Fig. 12: Distribution of suspension concentration for a different number of impellers $(\delta=1.34 \mathrm{~mm}, \operatorname{tank} H=2 D, \ell=0.5 d)$

Relationships of the relative standard deviations at different frequencies of the impeller rotation (for a different number of impellers) and their distribution are given in Fig. 13. It follows from these data that the lowest values of standard deviation (the highest homogeneity) can be achieved when using four impellers, placed at a distance of $\ell=d$ or three impellers at a distance of $\ell=1.5 d$. Hence, it may be concluded that homogeneity of the obtained mixture depends more on the location of the highest impeller than on the number of impellers. The highest homogeneity was achieved 


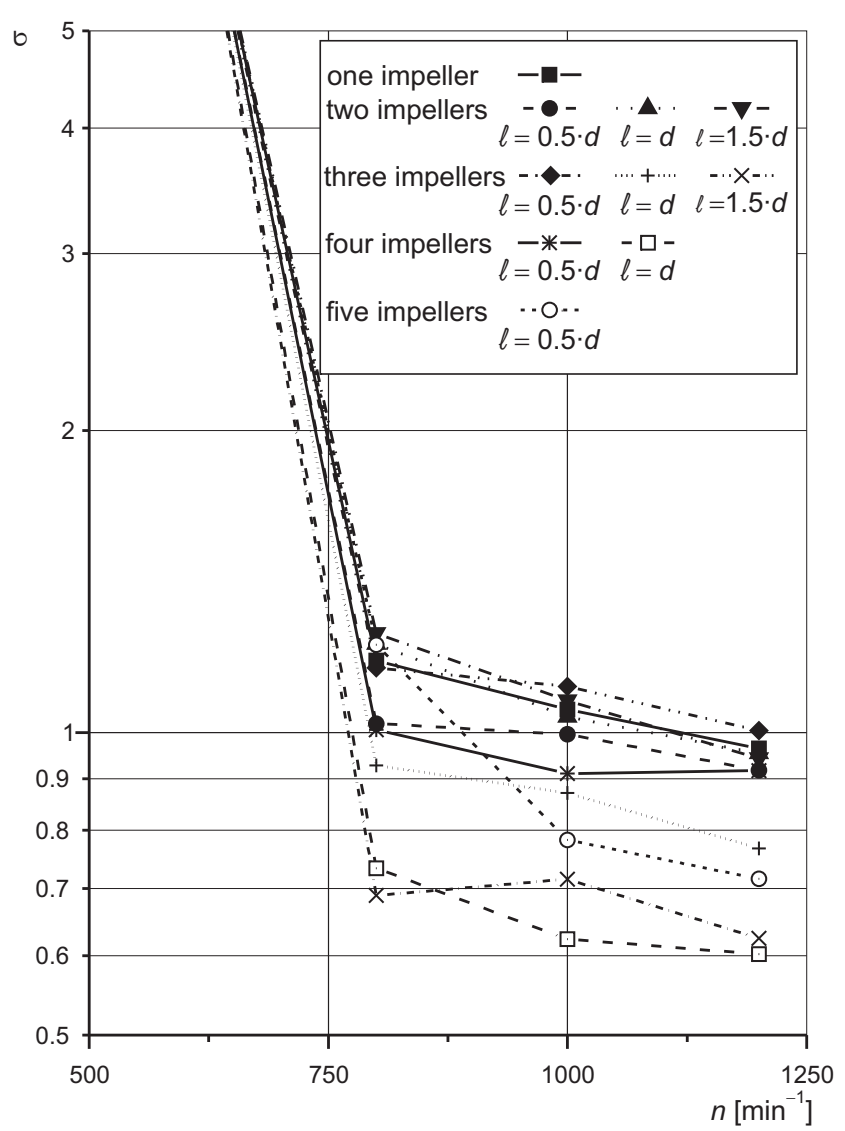

Fig. 13: Relative standard deviation of suspension concentration (particles $\delta=1.34 \mathrm{~mm}$ ) in the $\operatorname{tank} H=2 D$

when the highest impeller was at a distance of less than $0.8 \mathrm{D}$ from the liquid surface.

Application of the system with the highest impeller just in this position is also advantageous from the point of view of energy consumption, as shown by the dependence of standard deviation $\sigma$ on the energy criterion $\Pi_{s}$, shown in Fig. 14 .

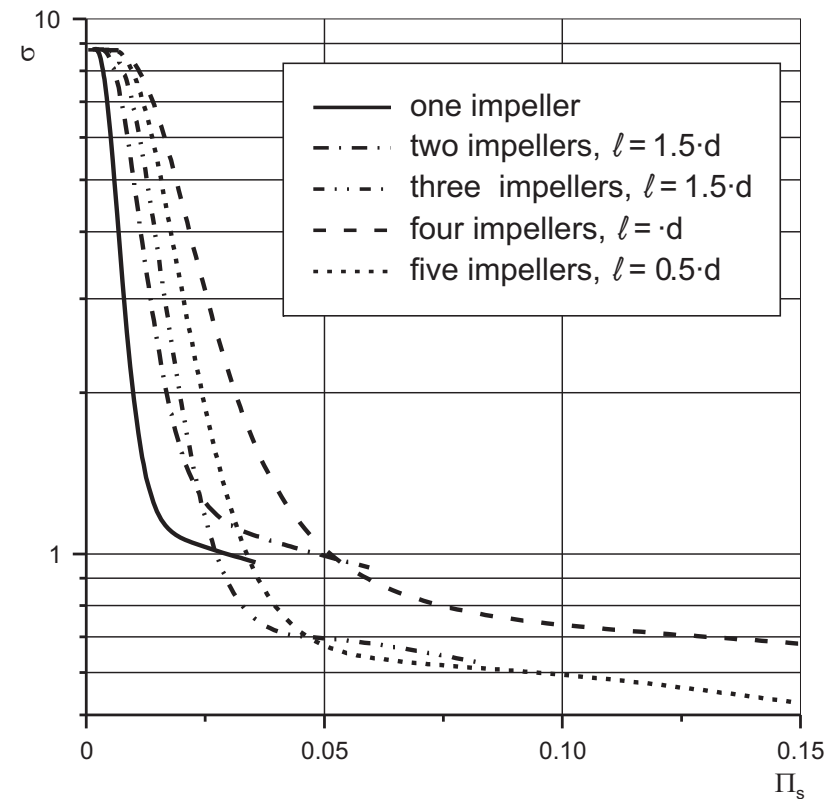

Fig. 14: Comparison of standard deviation and energy criterion for different number of impellers placed in the tank $H=2 D$ (particles $\delta=1.34 \mathrm{~mm})$

\section{Conclusions}

In order to produce a suspension it is not necessary to use a large number of impellers on the shaft in a standard tank $(H=D)$, but this results in increased homogeneity (especially of suspensions containing big particles).

In more slender tanks $(H=2 D)$ the state of solid suspension can be reached, but in the upper part of the tank there is only a continuous phase and there are practically no solid particles at all.

Homogeneity of the produced suspensions can be increased significantly by placing a larger number of impellers on the shaft in such a way that the highest impeller operates in the upper part of the tank.

On the basis of the results obtained in this study it is recommended to locate the upper impeller at such a level that its distance to the free surface of liquid in the tank is smaller than $0.8 \mathrm{D}$.

\section{Symbols}

$c_{\mathrm{i}} \quad$ solid concentration at a given point (volumetric)

$c_{\mathrm{m}} \quad$ mean concentration of the solid (volumetric)

D tank diameter, $\mathrm{m}$

d impeller diameter, $\mathrm{m}$

Fr' modified Froude number, Fr' $=\left(n^{2} d / g\right) \rho / \Delta \rho$

$\mathrm{Fr}_{\mathrm{cr}}{ }^{\prime}$ modified critical Froude number, $\mathrm{Fr}_{\mathrm{cr}}{ }^{\prime}=\left(\mathrm{n}_{\mathrm{cr}}{ }^{2} \mathrm{~d} / \mathrm{g}\right) \rho / \Delta \rho$

$g \quad$ acceleration of gravity, $\mathrm{m} / \mathrm{s}^{2}$

$H$ height of liquid in the tank, $m$

$h_{\mathrm{s}} \quad$ height of the suspension up to the suspension-water interface, $m$

$h_{\mathrm{v}} \quad$ height of the particles resting on the bottom, $\mathrm{m}$

$j \quad$ number of impellers on one shaft

$\ell \quad$ distance between impellers, $\mathrm{m}$

$n \quad$ frequency of the impeller rotations, $\mathrm{s}^{-1}$ or $\mathrm{min}^{-1}$

$n_{\text {cr }} \quad$ critical frequency of impeller rotations

$P \quad$ mixing power, $\mathrm{W}$

Po Power number, $\mathrm{Po}=\mathrm{P} /\left(\mathrm{n}^{3} \mathrm{~d}^{5} \rho_{\mathrm{z}}\right)$

$\delta \quad$ solid particle diameter, $\mathrm{m}$

$\Delta \rho \quad$ density difference, $\Delta \rho=\rho_{\mathrm{s}}-\rho$

$\rho \quad$ disperse phase density, $\mathrm{kg} / \mathrm{m}^{3}$

$\rho_{\mathrm{s}} \quad$ solid density, $\mathrm{kg} / \mathrm{m}^{3}$

$\rho_{\mathrm{z}} \quad$ suspension density, $\mathrm{kg} / \mathrm{m}^{3}$

$\sigma \quad$ relative standard deviation of the concentration

$\Pi_{\mathrm{s}} \quad$ criterion defined by Eq. (2)

The investigations presented in this paper were in part financed by a research project of the Ministry of Education of the Czech Republic (Project No. J04/98: 212200008).

\section{References}

[1] Rieger, F., Rzyski, E.: Dobór optymalnego mieszadta do procesu mieszania zawiesin ciała stałego w cieczy. (Selection of the optimum impeller for mixing of solid-liquid suspensions). Inż. Aparat. Chem. 1998, Vol. 37, No. 5, p. 19-23. 
[2] Rieger, F., Rzyski, E.: Mieszanie zawiesin w zbiornikach o różnej smuktości i liczbie mieszadet. (Mixing of suspensions in tanks of different fineness ratios and number of impellers). Zesz. Nauk. Polit. Łódzkiej (Nr 838), Inż. chem. i proces, 2000, Vol. 27, p. 221-226.

[3] Rieger, F., Rzyski, E.: Mieszanie zawiesin w zbiornikach z więssza liczba mieszadet. (Mixing of suspensions in tanks with an increased number of impellers). Inż. Chem. Proc. 2001, Vol. 22, No. 3E, p. 1213-1218.

[4] Bilek, P., Rieger, F.: Distribution of solid particles in a mixed vessel. Collect. Czech. Chem. Commun., 1990, Vol. 55, p. 2169-2181.

[5] Rieger, F.: Efficiency of agitators while mixing of suspensions. Proceed. of VI Polish Seminar on Mixing, Kraków Zakopane, 1993, p. 79-85.
[6] Novák, V., Rieger, F., Marisko, V., Mašín, L.: Power consumption and homogenization effect of multiple impellers in mixing in tall vessels. Congress CHISA, Prague, 1990.

Prof. Ing. František Rieger, DrSc.

e-mail: rieger@fsid.cvut.cz

Department of Process Engineering

Czech Technical University in Prague

Faculty of Mechanical Engineering

Technická 4, 16607 Praha 6, Czech Republic

Dr. Ing. Edward Rzyski

e-mail: erzyski@wipos.p.lodz.pl

Department of Process Equipment

Łódź Technical University

Faculty of Process and Environmental Engineering ul. Wólczańska 213/215, 90-924 Łódź, Poland 